\title{
On Collage as a New Language of Modernist Literature
}

\author{
Lu Xiang* \\ Zhejiang University, Yuhangtang road 866, Xihu district, Hangzhou, Zhejiang province, China \\ *Corresponding author. Email: carol-333xianglu@163.com
}

\begin{abstract}
With the acceleration and fragmentation in modern society, language is undergoing a paradigm shift under the impact of digital media. It is no coincidence that collage comes with modernity and becomes a new possibility of expression. In the context of modern and contemporary art and literature, it is necessary and feasible to deepen the academic research of collage. The modern times we live in is full of clues and juxtapositions of objects. Using traditional language to describe or record, it has long been unable to do well, and failed gradually. The grand system constructed by language through the referential function of words is falling apart. As a result, collage appeared in the expression system and became an "anti-narativity" expression. This formulation is similar to the "contre-discours", that Foucault once discussed. Collage, as a possible poetic theory and aesthetic concept, will also become an entrance to explore its connection with modernity and post-modernism, and rediscover the position of collage in the collage creation in literature and art. On the contrary, It also uses collage as the entrance to re-enter modern and contemporary literature and art.
\end{abstract}

Keywords: Collage, Modernity, Reproduction and Displacement, Contre-discourse, Anti-narativity.

\section{INTRODUCTION}

At the end of the 19th century and the beginning of the 20th century, prototypes of modern life emerged after the French Revolution and the Industrial Revolution. The industrial revolution promoted the birth of modern industry and mechanical civilization, gave birth to mass production and accumulation of things, and gradually built a modern consumer society. The quantitative change of things has brought about the qualitative change of urban life. As described by Baudelaire and Georg Simmel in Paris and Berlin, urbanites hurriedly mobilized their senses on the streets, "walking through this kind of traffic and pedestrians, involving individuals in a series of Panic and collision."[1] With the acceleration and fragmentation in modern society, language is undergoing a paradigm shift under the impact of digital media.

In the context of modern and contemporary art and literature, it is necessary and feasible to deepen the academic research of collage. First of all, we need to clarify the positioning and connotation of collage in this research: collage is not a concrete object, but a metaphysical creative aesthetic concept and paradigm.
How does collage evolve into an expression paradigm and aesthetic idea, the entry point for this metaphysical thinking is to explore the aesthetic principles and connotation of collage. Collage, as a possible poetic theory and aesthetic concept, will also become an entrance to explore its connection with modernity, and rediscover the position of collage in the collage-works in literature and art. On the contrary, It also uses collage as the entrance to re-enter modern and contemporary literature and art.

\section{WHAT IS COLLAGE?}

The word collage comes from French collage (a pasting). Etymologically it can be traced back to the old French coller (to glue) and the Greek kolla (glue). "Glue" means a glue that captures birds, and is a sticky substance extracted from plants such as holly and mistletoe. Originally used as a transitive verb, equivalent to "plaster". Its cognates also include the Latin gluten, which means to stick together, and the Lithuanian adjective glitus, which is equivalent to sticky. The definition of collage in the British Concise Encyclopedia is: "It refers to the pasting technique of pasting occasional materials, such as newspaper 
fragments, cloth pieces, wallpaper, etc., on a drawing board or canvas, and is often used in combination with painting."[2]The Hapercollins Dictionary of Art Terms and Techniques explains the concept of collage as "Collage is developed from paper collage (papier découper), and it is an art decoration in the 19th century that uses glued sheets of colored paper to make decorative patterns.' [3] Both definitions clearly show the tendency of collage understanding to lean towards the field of art. With the definition of collage, we have almost seen how artists use objects such as paper to reassemble and paste new images. At the same time, the objects such as photographs and papers mentioned in it also hint at the age when collage really appeared, which was not too long ago, at least after the age of replication technologies. As a technique, collage really originated from the field of arts and crafts. It first appeared in painting, and it is also a new form of artistic expression that only appeared in modern times. To sum up, the meaning of collage has shown a variety of parts of speech at the linguistic level: verbs, nouns, and adjectives. In the actual expression context, the appearance of the word collage can indicate a collaged work, it can also describe a technique of creation.

\section{COLLAGE IN MODERNITY AND ITS THEORETICAL CONTEXT}

In Western literary theory, modernity is a very important concept. It is not just an expression in the linear historical sense, but also a pivotal position in the history of thought. The change and spirit of the material world triggered by "modernism" (ism) The renewal of the world has formed a "modern" trend of thought, which contains a rich cross-media discourse. The rise and prosperity of collage in modern times are not accidents, but the inevitable result of profound philosophical support and poetic essence. It is doing its best to "imitate" modern times. With the turn of Socrates' literary creation from natural imitation to spiritual imitation, collage can explain its own imitation of modernity: It is not to describe the modernity based on a concrete description, but an attempt to "imitate" modernity formally and metaphysically. Based on this, it tries to use its own way to play the most important mission and function of literature and art, that is, to record and extend time.

The weird and strange modern times we live in is full of clues and juxtapositions of a large number of objects, filling every moment we experience. Using traditional language to describe or record, it has long been unable to do well, and failed gradually. The grand system constructed by language through the referential function of words is falling apart, and modern literature often only needs to pick up a fragment of it to form a small universe on its own. As a result, as a kind of "the endgame of literature"[4], collage appeared in the expression system and became an "anti-narativity" expression. This formulation is similar to the modern literary language that Foucault once discussed in The Order of Things: An Archaeology of Human Sciences to form a "contre-discours". Foucault believes that "literature must have its own existence, separate itself from all other languages, and form an unfathomable gulf, the only way is to shape it into a contre-discourse"[5], so that literary language can return to the language of itself. Scarlett Higgins believes that collage is "anti-narrative". The collage system composed of collage elements and the smallest unit is obviously different from the traditional language symbol system. It has no continuity and is full of uncertainty. Compared with the complete and central narrative mode, It is an expression of broken decentralization and fragmentation. Foucault's "contre-discourse" emphasizes that literary language has been shaken in the perspective of structuralism after the 17th century, and has no longer the function of recording and narrating discourse, and this is not the appeal of literature. "In modern times, literature has supplemented (rather than confirmed) the signification function of language." [5]And such a dualistic signification function still occupies a dominant position in Western literature in the 17 th century, when signs still existed In the duality of signification and representation, "literature is indeed composed of signifier and signified, so that they can be properly analyzed. Since the 19th century, literature has restored the existence of language on a certain day."[5]The 19th century was a sensitive point in time. In linear time, it began to be related to modern times, and this relation got deeper and deeper. It is this kind of "anti-narrative" and "contre-discourse" trends contained in modern times that make the integrity and narrative of literary texts continue to decline, and with it comes the decline of traditional interpretation methods. Collage was born at the end of dualistic language and became a new literary and artistic aesthetic language, providing a kind of "anti-narrative" and "contre-discourse" expression possibilities, and therefore it can better understand the modern spiritual meaning. To "imitate" the modern times we live in.

\section{THE AESTHETIC PRINCIPLES OF COLLAGE: REPRODUCTION AND DISPLACEMENT}

Walter Benjamin reflected on the problem of art in the era of mechanical reproduction, and declared the arrival of the era of technological reproduction, which, to a certain extent, gave birth to the logical premise of collage as manifestation of objects with objects themselves. Previous works of art emphasized the importance of "presence" and appeared in sacrificial and worship ceremonies. The works needed to be "present" and worshipped. Benjamin gave the artwork another layer of exhibition value on this basis. With the 
development of media and technological reproduction so far, even 3D printing technology has emerged. Things are not limited to paper printing or image reproduction. Various "repetitive" versions are added to various new situations and participate in the construction of new discourse. At the same time, the use of ready-made objects in the collage meets the demand for "fastness" in modern social life. It is a reflection and reflection of the rapid technological revival in the process of urbanization and the infinite acceleration of the social process. In such a historical context, collage first gained initial applause in art.

It was not until the beginning of the 20th century that collage had the possibility of becoming an aesthetic concept. Its clues and foundation are rooted in the emergence and widespread use of reproductive technology in the 19th century. Reproduction is essentially a kind of "repetition". The "repetition" before reproduction technology is a time-consuming and labor-intensive manpower project. The copyist monks in the Middle Ages worked hard in the copy room all their lives and were the most shocking witnesses to this project. The impossibility of technological reproduction is the shackles of the scribe, and it also blocks the possibility of transfer, reset and the dialogue, which not only obstructs the communication of literature, art, and culture, but also delays the citation and reference in creation, which form an intertextual reference between texts.

In a sense, collage represents the mechanism of function of symbols. Symbols originate from the naming and marking of things. It is the repeated and repeated use of a symbol to refer to a thing that finally determines the referential relationship between the symbol and the thing. The displacement of the object in the collage is actually a representation of the essential character of the symbol. The collaged material in the collage is actually a concrete object, so it is no longer a symbol that refers to the object. This is the difference between collage and language. Therefore, the concept of displacement in the collage contains obvious materiality and heterogeneity. Collage is more of a movement and transfer of objects, and the presence of objects implies the performative clues of collage-"speech is an act", and the act of collage means even more.

The similarity concept proposed by Foucault in The Order of Things: An Archaeology of Human Sciences is very illuminating for the understanding of the similarity of collage here. In Foucault's view, the composition and operation of the entire world are inseparable from the principle of similarity, "it is the creator of Western cultural knowledge", "it is the similarity that largely guides the interpretation and interpretation of the text; It is the similarity that organizes the game of symbols. It is the art of human beings to recognize all kinds of visible and invisible things, and to guide the representation of these things." [5]it can be understood in general and simply as the existence of this world. All the natural things are summoned by symbols, words, and language through similarity and the abstract and metaphysical relationship between them is similarity. In collage, the similarity I want to talk about is also a kind of "similar" relationship. It can even be said that the similarity principle of collage is the "similarity" of this kind of universal principle in the Foucault sense; it is a concrete representation of the concept similarity in the collage. When collage is discussed as a kind of aesthetic logic and concept, this similarity is definitely not the exact fit and tally of the borders of two pieces of paper, but a kind of implicit or explicit metaphysical connection. The recessiveness of this relationship even leads to the opposite of similarity, that is, contrast and opposite. Therefore, when we interpret collage, we often see that different objects and unrelated objects are glued together. This only depicts the appearance. To understand the similarity of how Foucault's words conjure things, then all the represent objects and the represented objects must be "similar".

Foucault distinguished four subtypes of similarity: suitability (convenientia), simulation (aemulatio), analogy (l'analogie) and sympathy (des sympathies). First of all, it is suitable for emphasizing the proximity or even connection of locations on the one hand, and the "similarity of space and place" between protruding objects. On the other hand, it is also for communication after proximity, thus possessing the similarity of attributes. For example, "body and spirit are suitable of the both sense"; secondly, simulation, this similarity overcomes the distance of space, the similar things can be separated from each other, and they are "natural twins of existence and things". They are similar in no particular order, but there is difference of strong and weak; the third similarity, the analogy coincides simulation with suitability, which can span space and echo with each other,at the same time be similar and suitable with each other. "Talking about cooperation, connection and joining", they are not the visible similarities between things, but subtle similarities of the relationship between things. The stars to the night sky can be "analogized" to plants to the land; sympathy, as the fourth smimlarity is perhaps the most hidden and abstract similarity. There is no path, distance, and connection. It is a principle of movement that makes the sunflower rotate with the sun and the root stretches out to the water. These similarities are nothing more than clarifying the different forms of how things are related.

Therefore, in understanding the concept of collage's similarity and understanding of the collage material and its representational effects based on similarity, we can get clues and enlightenments from Foucault's universal concept, because collage is a creative aesthetic or, when talking about the concept of poetry, it is not a collage in a concrete sense. The similarity is therefore not a 
question of the similarity between a piece of paper and another thing. To a certain extent, this explains the potential of collage work to explode indescribable interpretation after collage of simple materials, as well as the huge possibility of expression.

Bruno Latour uses "Paperwork" in his article Visualisation and Cognition: Drawing Things Together to describe the practice of displacement of various elements in the context of cognitive science. The practice of displacement here is to use words for scientific things. Symbols and images are represented and depicted. This also verifies the possibility of "displacement" with the "referencing" between symbols before. In this regard, he emphasized the importance of inscription to science. He gave, for example, "The manipulation of substances in gallipots and alambics becomes chemistry only when all the substances can be written in a homogeneous language where everything is simultaneously presented to the eye." [6]Because those printed matter and inscriptions themselves are a kind of premise of the displaced possibility of things. Just like when a scientist shows his own discovery, he can't really show a star or a tiny bacterium on the spot. Usually they can only use this kind of thing based on the plane displacement of images and words to convey their scientific knowledge and discoveries. This is reflected in the extensive use of data and images in various scientific reports to depict large or too small immovable objects in nature. What Latour examines is how these three-dimensional scientific objects are transformed into displaceable flat images. This process of flattening objective three-dimensional things can be expressed as "referential" in traditional epistemological language. Compared with collage in art, the process of Latour's research seems to be the reverse process of collage. That is, the objective three-dimensional object enters the two-dimentional representation.

From the description of the title "Drawing things together", it is not difficult to see the interesting contrast between the two. The object of scientific research is the three-dimensional things in the objective nature, and the final refined and abstract method is drawing. The credibility of "inscription" in science depends on how many "allies" it can "mobilize" - that is, the discourse, theory and context behind things themselves, which are cited by scientific papers. The necessity of citation lies in "You doubt of what I say, I'll show you."[6]This is different from the quotation in literary texts, which is a present form of collage-aesthetic in literature. The expressive function of the collaged things depends on the context and discourse of the collaged images. The established referent background is also mobilizing one's allies to achieve the purpose of expression and performance.

Latour returned 9 advantages of displacement: 1 . Mobile: We can't move the earth, but we can take a globe. 2. Immutable: it will not change during the displacement. The characterization itself does not change when it is transferred, and the objects it can manifest also remain constant during this process. 3 . Flat: Everything is clearly laid out on a flat surface. 4. Adjustable proportions: The real relationship between various volumes of things can be changed when they are displaced. For example, an earth can become the size of a ball in a child's hand, and a star can be represented smaller than bacteria. 5. Easy to reproduce and disseminate; 6 . Things can be rearranged and combined. 7. Different theories can be connected and integrated. 8 . The text and the world are connected through the laboratory. 9. The world is geometricized by displacement. [6]

The characteristics and advantages of these displacements are also fully reflected in the creative process of collage. The process of collage is the process of object displacement. Latour studied how real things are displaced into a two-dimensional plane, which actually points out the important significance that scientific things can bring to science after they establish a referential relationship on the two-dimensional plane. The creative logic of collage focuses on how to map the real and objective world through the representation system, and thereby expand the functions of metaphor and representation, especially the representation of modernity and modernity. Latour's point of view of "Inscriptions allow conscription!" mentioned in this article is placed in a literary context and involves the issue of "citation" in the aesthetics of collage creation. It is also an important clue in the study of collage creation aesthetics. It cannot be said that Latour's sociology of science is also inspiring and guiding the aesthetics of collage creation in literature and art.

Latour said, "Without the displacement, the inscription is worthless; without the inscription the displacement is wasted" [6]Latour's mention and research on inscriptions based on the scientific sociology actually affirmed the important function of the symbol system and images for the displacement of things. At the same time, it is affirmed that only after this displacement, many important discoveries and thoughts can be expressed and presented. Compared with the objectively existing things themselves, these displaced dualistic representations are the truth and essence.

Based on the above discussion on the meaning of collage, the meaning of collage is the displacement based on reproduction and the expression of heterogeneity. At the same time, compare with Foucault's theoretical results, that the world is based on similarity to build the interrelated references, collage has the potential to become a modernist literary language of "anti-discourse" and "anti-narrative". 


\section{A GLIMPSE AT COLLAGE IN LITERATURE THROUGH THE EYES OF LITERARY WRITERS}

Michael Ondaatje who wrote The English Patient, and Kazuo Ishiguro, who wrote The Remains of the Day, both expressed their preference for the application of collage techniques to writing. Through the statements of these two well-known literary authors, collage once again stood under the light on the stage of the modernist literary stage. Ondaatje said: "I like collage, before the word 'collage' appeared. That's how I write poems. I like to put things that have nothing to do with each other together, and the same is true for writing novels. There are various things in The English Patient." [7]This statement of Ondaatje actually has two meanings. First, he acquiesced in the legitimacy of collage as a creative logic and technique in literary creation. Second, with his work The English Patient, he recognized the collage aesthetic of grafting of different time and space in the literary text, and the gathering of characters and events in different stories that seem to be far apart. In modern and contemporary literary creation, the linear narrative is broken, multi-line stories go hand in hand, interlinked, refer to each other, and form a special intertextual effect within the text. Works that adapt to this aesthetic concept of creation have almost become the distinctiveness of "modernist novels". The modernity written in the collage itself makes it universally appear in modernist literary works, which coincides with the representational needs of this era, making it gradually become a modernist literary expression paradigm-even though each writer still shows creations diversity in their works under.

Kazuo Ishiguro also mentioned in the conversation with Ondaatje that he likes to put stories with different chapters in different timelines, and there is an internal connection between the chapters. Therefore, even if he is used to writing in the first person, he can still be as free as a collage artist. In Ishiguro Kazuo's personal description, the "I" in his writing, as a narrative subject, is free and concealed. It can be told invisibly, and it can also collage characters and time from the perspective of God to disrupt the logic of writing makes the development of the chapter plot appear back and forth and advance in a roundabout way, thereby creating a defamiliarization effect. Such an effect, in turn, helps the narrative subject to hide itself, because subject construction always tries to obtain a wholeness with a complete and unified value cognition, and this must be supported by the text, but the collage-Logic in the text is constantly disrupting and interrupting the "wholeness" or the "completeness" of the subject. He bluntly said: "I don't want to be locked in a complete story structure, but I often deliberately conceal this approach, and often spend a lot of effort trying to make the transition between the two chapters as invisible as possible." He covered and dodged his collage creation in words, avoided constructing a complete narrative subject, and has no intention of completing the overall plot. The "wholeness" or the "completeness", which has been broken into pieces countless times in modernist novels. These pieces are the object of collage and also the subject of collage.

Kazuo Ishiguro used the "unlocated moment" to describe the principle of his collage creation, that is, a certain line of a dialogue in a scene is used as a clue, which fixes also the time at the moment of the line, and when the same line appears in another scene, this first scene is through this line led to another time and space. In this way, several time and space can be connected in the narration. Ishiguro Kazuo added: "I am very resistant to developing the storyline in chronological order.'[7]

The appearance of collages in literature has actually a clue since early in the literary history. Fairytale writer Andersen used to cut and paste some other books or paper patterns in his own works, and add his own words to it. The french writer Hugo also used paper and patterns to collage them on a dark background and then painted on this basis. As a poetic expression, it has strong uncertainty and metaphysics. Therefore, the proposal of collage poetics is also based on such a "metaphysical" understanding, and analyzes and studies collage as a aesthetic of creation or a poetic concept.

\section{CONCULUSION}

Literature is facing new challenges and opportunities in the 20th century. Finding a new language of literature is the demand and tireless pursuit of all literary creators. It is not a coincidence that we can find collage in many works of modernist writers. After excavating and refining collage based on the principle of repetition and displacement, collage is not only a concrete modern product, but a new literary language with the potential to represent modernity, and it also meets to the repeated in modern literary language mentioned expectations of "Anti-narrative" and "anti-discourse".

The associations between language and objects, objects and objects based on the similarity in the Foucault sense, and the associations between collage objects in collage, also have referential relationships and potentials based on similarity, also Therefore, it becomes another kind of linguistic rationality that can be analogized to logic of words summon the reality. Moreover, the presence of the innate heterogeneous material in the collage, and the mixed characteristics after the reorganization, make it naturally related to modernity from the linear historical dimension and the qualitative characteristic dimension, and therefore it is a better paradigm to "imitate" the modern times and realized the function of recording and extending the time of literary language. Regardless of the era, for literary 
creators, trying to break through the distinction between literary and artistic categories and continuously expand the dimensions and possibilities of literature is a tacit understanding of the creators that coincides with each other and is self-evident. And this tendency of creation and breakthrough is more prominent in modern and contemporary literary and artistic works. As a kind of creative aesthetics, collage remains present without exception, and it has been corroborated in many transnational literary text cases. The creation and reflection support of literary giants who have won the Nobel Prize for literature are all for the aesthetics of collage creation in modern and contemporary times, which is testimony of the presence of collage-aesthetic in literary works.

\section{REFERENCES}

[1] Baudelaire, Selected Essays on Baudelaire Aesthetics, translated by Hong'an Guo, People's Literature Publishing House, Beijing, 1987, p.482-483.

[2] British Encyclopedia 3, edited by Encyclopedia Britannica, China Encyclopedia Press, Beijing, 2011, p.1325.
[3] Ralph Mayer, The Hapercollins Dictionary of Art Terms and Techniques, edited and revised by Steve Sheehan, translated by B558Group of Qinghua University, Central Compilation\&Translation Press, Beijing, 2008, p.74.

[4] Scarlett Higgins, Collage and Literature. The Persistence of Vision, Routledge Taylor \& Francis Group, New York and London, 2019. p.1.

[5] Michael Foucault, The Order of Things: An Archaeology of Human Sciences, translated by Weimin Mo, SDX Joint Publishing House, Shanghai, 2016, p.47.

[6] Bruno Latour, Visualisation and Cognition: Drawing things together, in: H. Kuklick (ed.): Knowledge and Society Studies in the Sociology of Culture Past and Present, Jai Press vol. 6, 1986, p.13.

[7] See the dialogue between Michael Ondaatje and Kazuo Ishiguro published in the issue of The Beijing News of July 14, 2018: People have forgotten that creation comes from improvisation, 2018 